attempts to reduce undesirable side effects, namely, liability to produce addiction and depressant effect on the respiratory centre, but such modifications had not yet resulted in a compound which had significantly replaced morphine as a clinical agent. The alternative approach of synthesizing fragments of the morphine molecule had resulted in the production of the morphinans and benzomorphans which represented the greatest achievements in this direction. These studies clearly emphasized the importance of the phenolic, alcoholic and basic groupings. Stereochemical factors played an important part in analgesic activity since, with enantiomorphs, one isomer was always more active than the other and in some synthetic analgesics the most active enantiomorphs were related to $\mathrm{D}-(-)$-alanine. Various studies had led to the hypothesis that in the mediation of analgesic activity a three-dimensional fit at a 'receptor site' was involved and stereochemical implications could be important in the separation of desirable and undesirable pharmacological effects. It was probable that the chief factor limiting the intensity of response and duration of effect of morphine and the synthetic analgesics was biotransformation, and in these transformations the phenolic grouping played an important part. $N$-dealkylation also had important pharmacological implications following from two provocative hypotheses; one relating it to analgesic action, and the other to the development of tolerance.

Chemistry and Biosynthesis of Ipecacuanha Alkaloids. Dr. H. T. Openshaw (Wellcome Research Laboratories, Beckenham, Kent) dealt chiefly with the chemistry of the alkaloids and said that they formed a group of inter-related isoquinoline alkaloids of unique structure, the biogenetic relationship of which to the benzylisoquinoline group was of particular interest. The structure of emetine was established by classical methods of degradation, but in its final stages this investigation received powerful support from the developments in biogenetic theory then current; in turn, the biogenetic theory was strongly upheld by the discovery in ipecacuanha of a postulated intermediate in the biosynthesis. Considerable significance was also attached to the stereochemistry of the alkaloids and their relationship to that of the cinchona and indole series. The absolute configuration of each of the four asymmetric centres in emetine had been established, and attention had been paid to the problem of stereospecific synthesis of the alkaloid. A feature of special interest in the chemistry of emetine was its conversion by mild oxidation into a series of dehydrogenation products, the structure of which had been elucidated.

Pharmacologically, emetine was of considerable importance for its amœbicidal activity, and of special interest in that all the stereoisomers and closely related compounds arising from the synthetic work, only one other substance, 2-dehydroemetine, showed comparable activity.

The symposium therefore proved to be well balanced and showed the value of studies on the location and variation in alkaloids of opium, as a background to results obtained using tracer techniques. Classical chemical investigations, in particular with stereochemical considerations, were of benefit to pharmacology and the work on the ipecacuanha alkaloids formed an interesting comparison with studies on morphine and its related compounds.

S. B. Challen

\title{
THE NATIONAL PARKS COMMISSION
}

T THE twelfth annual report of the National Parks Commission. for the year ended September 30, 1961, besides providing the customary concise and very readable illustrated account of the activities of the Commission during the year, progress in the national parks and with the long-distance routes, is marked by two notes of anxiety *. First, the Commission is anxious that amending legislation to the National Parks Act of 1949 should not be long delayed. Apart from the practical benefit expected to follow the adoption of the recommendations submitted to the Minister, the Commission believes that reappraisal in Parliament of the working of the Act would give welcome encouragement to those whose duty it is to administer the Parks and would help to produce in the public mind a clearer conception of the whole idea of national parks. The second note of anxiety relates to the continuing proliferation of aerial masts throughout the countryside, usually on remote and unobstructed high ground. These increasing coverage demands appear as yet to be entirely unco-ordinated, and while the Commission recognizes the need, it is far from satisfied that the problem of mast-sharing receives adequate consideration.

* National Parks and Access to the Countryside Act, 1949. Twelfth Report of the National Parks Commission for the year ended September 30, 1961. Pp. vi $+91+8$ plates. (London: H.M.S.O., 1962.) 7s. net.
The magnitude of the development issue is shown by the fact that during the year nearly 450 proposals for development affecting landscape beauty in national parks, in areas of outstanding natural beauty, or elsewhere were referred to the Commission by Government departments, park or other local planning authorities, or by amenity organizations. One notable success during the year recorded in the report is the decision of the North-Western Electricity Board to place the entire Upper Borrowdale scheme underground at its own expense, notwithstanding the offer of contributions from the Friends of the Lake District and the official consent to the placing of certain sections of the line overhead. Regarding areas of outstanding natural beauty, the report comments that review of the work done by the local planning authorities indicated that while the preservation of these areas from unsightly development was receiving full attention, insufficient use was made of the opportunities for positive action for the enhancement of natural beauty which would earn payment of the special 75 per cent rate of Exchequer grant. Some progress is reported with the long-distance routes, notably with the Dorset Coast Path, on the South Downs route, and field work on a North York Moors and a Yorkshire Court Path. One of the two remaining major problems of the Pennine Way has been solved, completing the Path within the Peak District National Park. 